\title{
In Vitro Assessment of Tobacco Smoke Toxicity at the BBB: Do Antioxidant Supplements Have a Protective Role?
}

\author{
Mohammed Hossain ${ }^{1,2}$, Peter Mazzone ${ }^{3}$, William Tierney ${ }^{4}$ and Luca Cucullo $5^{5^{*}}$
}

\begin{abstract}
Background: Tobacco smoke (TS) contains highly reactive oxygen species (such as hydrogen peroxide, peroxynitrite, etc), which cause oxidative damage in vascular tissue and may exacerbate inflammatory events leading to the blood-brain barrier damage (BBBD) which accompanies the development of a variety of neurological disorders. Smokers often have elevated leukocyte counts (primarily neutrophils and monocytes), and significant decreases in plasma alpha-tocopherol (vitamin E) and ascorbic acid (vitamin C) levels due to increased anti-oxidative mobilization in response to oxidative stress evoked by TS. For this purpose, using static culture systems and a well-established dynamic in vitro BBB model (DIV-BBB) we tested the hypothesis that antioxidant vitamin supplementation ( $E$ and/or $C$ ) can protect the BBB during exposure to whole soluble TS.

Results: TS exacerbates inflammatory events and leads to endothelial overexpression of vascular adhesion molecules (VCAM-1, P-selectin and E-selectin), release of pro-inflammatory cytokines (TNF- $\alpha$ and IL-6) and nitric oxide (NO), release and activation of matrix metalloproteinases (MMP-2 and MMP-9), monocytic maturation into macrophages, and adhesion to the vascular endothelium. Furthermore, TS altered the normal glucose metabolic behaviour of in vitro BBB capillaries and caused a period of transient anaerobic respiration to meet the cellular bioenergetic demand. Pre-treatment with antioxidant vitamins ( $C$ and/or $E$ ) effectively reduced the proinflammatory activity associated with TS, protecting the viability and functions of the BBB.

Conclusion: Our results have shown that loss of endothelial viability as well as BBB function and integrity caused by TS exposure can be prevented or at least reduced by normal physiologic concentrations of antioxidant vitamins in vitro.
\end{abstract}

\section{Background}

Tobacco Smoke affects vascular endothelial physiology Active and passive tobacco smoke are associated with dysfunction of vascular endothelial physiology [1-13] in a causative and dose-dependent way. In the brain, TS increases the risk of silent cerebral infarction (SCI) [14] and stroke which by approximately $50 \%[15,16]$ due to its; pro-coagulant and atherogenic effects $[17,18]$. The risk increases proportionally with the number of cigarettes smoked [19]. Furthermore, oxidative stress caused by the exposure to TS can facilitate the pathogenesis and progression of several neurological disorders

\footnotetext{
* Correspondence: luca.cucullo@ttuhsc.edu

${ }^{5}$ Pharmaceutical Sciences, Texas Tech University Health Sciences Center, Amarillo, TX 79106 USA

Full list of author information is available at the end of the article
}

including Parkinson's and Alzheimer's diseases [20-24]. Previous study has shown that chronic smokers have a higher incidence of small vessel ischemic disease (SVID) than non-smokers [25]. SVID is a pathological condition characterized by leaky brain microvessels and loss of BBB integrity. Since TS generates superoxide and other ROS, some of the adverse effects of smoking may result from oxidative damage to ECs, [4,12,13,26-29], which may be aggravated by nitric oxide (NO) and antioxidant depletion (e.g., ascorbic acid). Recent observations strongly suggest that ROS are key mediators of $\mathrm{BBB}$ breakdown [25,26,30-33].

While the harmful effects of smoking on public health have been well demonstrated and detailed in many organs, the $\mathrm{BBB}$ has received much less attention despite the strong evidence for an association between
C Biomed Central

() 2011 Hossain et al; licensee BioMed Central Ltd. This is an Open Access article distributed under the terms of the Creative Commons Attribution License (http://creativecommons.org/licenses/by/2.0), which permits unrestricted use, distribution, and reproduction in any medium, provided the original work is properly cited. 
tobacco smoke and vascular impairment $[28,34]$. Our recently published data [25] have shown that TS promotes the pro-inflammatory activation of BBB EC and the release of pro-inflammatory mediators. This occurred in the absence of other pro-inflammatory stimuli and independently from the presence of peripheral blood cells. Furthermore; TS can significantly exacerbate the loss of BBB integrity caused by concurrent cerebrovascular rheological alterations, $[25,35]$ facilitating the further pathogenesis and progression of secondary brain injuries.

\section{Tobacco smoke: A harmful cloud of Free Radicals}

The role of free radicals in the pathogenesis of smokingrelated diseases has been substantiated by a large number of studies. A free radical is a highly unstable and reactive molecule containing one or more unpaired electrons. Free radicals, despite being essential for biological systems [36] have a potential to cause extensive oxidative damage to cells and tissues if their levels become excessive [21,22,27,37-41]. At the vascular level free radicals can lead to oxidative damage of endothelial cells $[12,13]$ (e.g., DNA strand breakage $[3,42-44]$ ) and inflammation [3]. Free radicals arise normally during cell metabolic activity and are also purposefully produced by immune cells to neutralize potentially harmful pathogens such as bacteria and viruses. In vivo, under normal circumstances the oxidative stress caused by naturally generated free radicals is counterbalanced by antioxidants [45,46] (e.g., alpha-tocopherol, ascorbic acid, beta-carotene, glutathione, catalase, superoxide dismutase, etc.). However, environmental factors including active and passive tobacco smoking (a major exogenous source of free radicals contained in both gas phases and $\operatorname{tar}$ [47-49]) can spawn these highly reactive oxygen species (ROS; e.g., hydrogen peroxide, epoxides, nitric oxide (NO), nitrogen dioxide, peroxynitrite (ONOO-), etc [49]) beyond the levels which the human body can eliminate effectively. In fact, several studies have shown that 1) chronic smokers suffer of antioxidants shortage caused by the increased demand that the ROS derived from TS place on their cells $[13,50,51]$; 2) antioxidant supplementation reduces the oxidation and inflammation induced by tobacco smoke in animals and cells [13,50,52-55]. In response to these studies, the Food and Nutrition Board of the National Academy of Sciences has established a higher Recommended Dietary Allowance (RDA) of vitamin C for smokers, (more than 200 $\mathrm{mg} /$ day) versus the recommended $90 \mathrm{mg} /$ day for nonsmokers.

Is there a role for Antioxidant Vitamins Supplementation? Antioxidants such as vitamin C (ascorbic acid) and $\mathrm{E}$ ( $\alpha$-tocopherol) are compounds that hinder the oxidative processes and thereby delay or prevent oxidative stress. Although there is still no unequivocal evidence that an increased intake of antioxidant nutrients can fully counteract TS toxicity, there are many supporting data suggesting that antioxidants may prove to be effective scavengers of exogenous-derived ROS [56]. Previously, vitamin $C$ has been shown to act not only as a potent reducing agent but also to play a role (currently not yet clearly understood) in modulating the production of lymphocytes and cytokines, the activity of phagocytes, and the expression of a number of cell adhesion molecules in monocytes [57]. Furthermore, vitamin C seems to prevents histamine release and increases the detoxification of histamine [58], thus acting as an anti-inflammatory agent as well as a potent antioxidant. Considering the major role played by ROS in the pathogenesis of BBB impairment as well as that of neurological disorders [21-23,32,59] we evaluated the independent and complementary effectiveness of antioxidants vitamins supplementation, such as vitamin $C$ (protection against protein oxidation [60-62] and vitamin E (counteract lipid peroxidation [63-65]), in shielding the BBB from the chronic exposure to TS-generated oxidative stress.

\section{Results}

Tobacco Smoke pro-inflammatory response induced in brain microvascular endothelial cells was reduced by antioxidant vitamins supplementation

Chronic exposure of confluent cultures of human brain microvascular endothelial cells (HBMEC) to TS (equivalent to 20 cigarettes/day; see in Material and Methods for details) resulted in a significant increase in the number of HBMEC cells expressing the pro-inflammatory adhesion molecules P-selectin, VCAM-1 and E-selectin the expression levels of P-selectin, VCAM-1 and Eselectin $(112.5 \% \pm$ SEM 8.2, $144.5 \% \pm$ SEM 6.3, and $84.3 \% \pm$ SEM 12.4 respectively) as compared to shamsmoke-exposed controls (Figure 1A). The augmented expression of these pro-inflammatory adhesion molecules was paralleled by over a 10 fold increase (from 9.1 \pm SEM 2.1 to $103.3 \pm$ SEM $4.3 \mathrm{pg} / \mathrm{mL}$ ) of interleukin-6 (IL-6) levels in the medium, and over a 2 fold increase in that of tumor necrosis factor-alpha (TNF- $\alpha$ ) (from $25.8 \pm$ SEM 4.5 to $67.2 \pm$ SEM $9.0 \mathrm{pg} / \mathrm{mL}$ ). IL- $1 \beta$ levels were unaffected (Figure 1B). Exposure to TS also increased the release of matrix metalloproteinases-2 (MMP-2) from $775 \pm$ SEM 98 to $4344 \pm$ SEM $235 \mathrm{pg} /$ $\mathrm{mL}$. No release of MMP-9 was detected (Figure 1C). Gelatin zymography of electrophoresed medium samples showed a small $(28.3 \pm$ SEM $9.0 \%)$ yet significant increase in MMP-2 activity 15 minutes following TS exposure, which substantially increased to $132.7 \pm$ SEM $14.3 \%$ at 60 minutes (Figure 1D). 


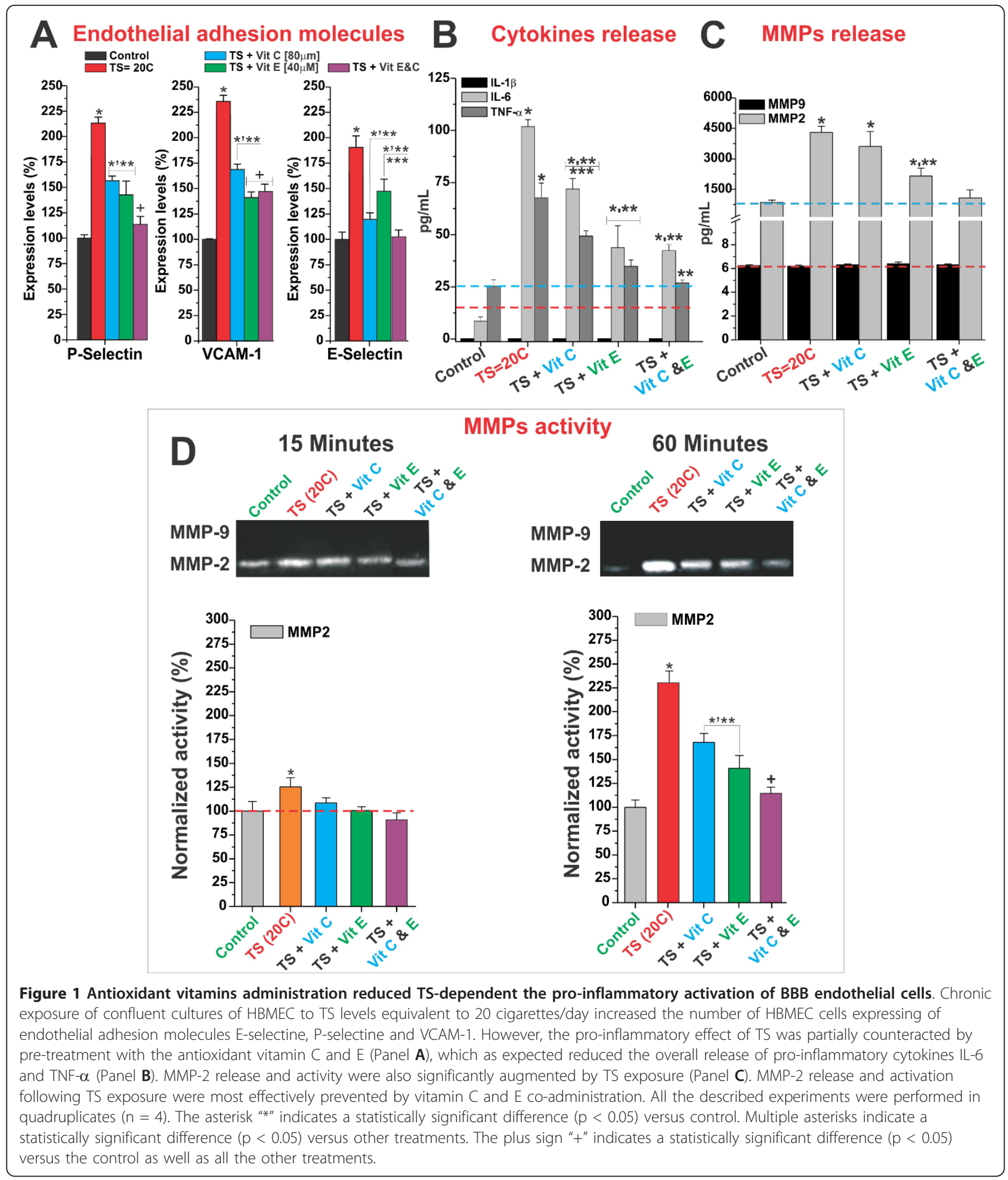

Pre-treatment with vitamins $\mathrm{C}$ and/or E (final physiological concentrations $\cong 80$ and $40 \mu \mathrm{M}$ respectively) significantly reduced the pro-inflammatory activity of TS on HBMEC. Specifically the over-expression of endothelial adhesion molecules during TS exposure (Figure 1A) was significantly reduced. This was paralleled by a decrease in the release of IL-6 and TNF- $\alpha$ (Figure 1B). MMP-2 release (Figure 1C) and activity (Figure 1D) were reduced in cultures pre-treated with vitamin $\mathrm{E}$ and $\mathrm{E}+\mathrm{C}$ (combined treatment) but not vitamin $\mathrm{C}$ alone. 
Overall, the combined treatment showed the most effective protection against TS exposure.

\section{Monocytes activation by Tobacco Smoke was partially inhibited by pre-treatment with vitamin $\mathrm{C}$ and/or vitamin E}

Our results showed a very marked increase of TNF- $\alpha$ (from $0.81 \pm$ SEM 0.14 to $163.11 \pm$ SEM $7.83 \mathrm{pg} / \mathrm{mL}$ ) and IL- $1 \mathrm{~b}$ (from $0.66 \pm$ SEM 0.21 to $113.59 \pm$ SEM 8.15 $\mathrm{pg} / \mathrm{mL}$ ) levels in the culture medium of THP-1 monocytes upon exposure to TS (see in Materials and Methods for details) (Figure 2A). IL-6 level was only moderately effected but the difference was not statistically significant. In parallel, we observed a significant increase in the medium levels (Figure 2B) of MMP-9 and MMP-2 (from $285.71 \pm$ SEM 22.44 to $596.55 \pm$ SEM $49.68 \mathrm{pg} / \mathrm{ml}$ and from $1638.56 \pm$ SEM 1095.34 to $12089.50 \pm$ SEM 912.28 pg/mL respectively). Increased MMPs activity (MMP-2 and MMP-9) was already evident after 15 minutes of TS exposure (62.9 \pm SEM 4.4\% and $26.4 \pm$ SEM $3.8 \%$ respectively; see Figure $2 \mathrm{C}$ ) and became significantly more prominent at 60 minutes (151.9 \pm SEM 8.8\% and $60.5 \pm$ SEM 5.6\% respectively).

TS-triggered release of pro-inflammatory cytokines was most significantly reduced by pre-treatment with vitamins $C$ and $E$. In contrast to vitamin $C$, vitamin $E$ alone also demonstrated significant anti-inflammatory protection.

The TS-induced release of MMP-2 and MMP-9 was also decrease by the antioxidant vitamins however, there were no statistical significant differences in terms of efficacy between individual (Vit. C or E) and combined pretreatments. By contrast, the most effective blockade of MMPs activation was attained using combined $(C+E)$ vitamins supplementation (Figure $2 \mathrm{C}$ ). Vitamin $\mathrm{E}$ alone was also effective while only short term MMPs activity reduction was observed when using vitamin $C$ (Figure $2 \mathrm{C}$ left panel).

\section{Antioxidant vitamins reduced endothelial-monocytes adhesion and synergistically decreased the release of pro- inflammatory mediators during TS exposure}

HBMEC and THP-1 cells cultures were individually exposed to TS as described above. Parallel sham-smoke cultures were used as control. After the TS exposure cycle was completed, the wells containing the endothelial cells underwent a wash out and medium replacement using a TS-free one. In parallel, THP-1 cells were isolated by centrifugation, then re-suspended $\left(2 \times 10^{5}\right.$ cells $/ \mathrm{mL}$ ) with the endothelial cells and left to undergo adhesion for one hour without agitation. Non-adherent monocytes were then washed away by gentle shaking and the medium was collected for a content analysis of pro-inflammatory mediators (cytokines and MMPs).
Visual inspection (Figure 3A upper panels) and quantification of adherent monocytes (Figure 3A lower panel) showed a dramatic increased in the percentage of monocytes bonded to endothelial cells following TS exposure $(90.3 \pm$ SEM 5.0\%) in comparison to sham-smoke cultures (23.6 \pm SEM 5.2\%). Pre-treatment with normal physiological concentrations of vitamins $\mathrm{E}$ and (to a lesser extent) $C$ reduced the percentage of adherent cells in TS pre-exposed cultures (66.2 \pm SEM $4.6 \%$ and 47.4 \pm SEM $6.7 \%$ respectively). The combined pre-treatment with both vitamin $\mathrm{E}$ and $\mathrm{C}$ was the most effective $(36.8$ \pm SEM 4.0\%). As previously observed in addition to enhanced endothelial-monocytes adhesion, TS exposure lead to a significant increase in the medium content of IL-1 $\beta$, IL- 6 and TNF- $\alpha$ (0.58 \pm SEM 0.5 to $112.2 \pm$ SEM $29.01 ; 5.01 \pm$ SEM 2.2 to $109.3 \pm$ SEM 33.7; $62.5 \pm$ SEM 29.8 to $328.6 \pm$ SEM $34.9 \mathrm{pg} / \mathrm{mL}$ respectively). Antioxidant vitamin pre-treatment was effective (at various levels) in reducing the TS-induced release of these proinflammatory cytokines (Figure 3B1). As expected, culture medium analysis showed that the interaction between TS-activated THP-1 cells with TS-activated HBMEC prompted a synergistic increase in the release and activation of MMP-2 and MMP-9 (Figure 3B2 and 3B3). Vitamin $C$ reduced the release of MMP-2 and MMP-9 but was ineffective in blocking their corresponding activation as demonstrated by the zymogram gel analysis of medium content (Figure 3B3, upper panel). By contrast the anti-inflammatory protection provided by vitamin $\mathrm{E}$ and the combined treatment $(\mathrm{C}+$ E) were significantly more effective.

\section{Ascorbic acid and $\alpha$-tocopherol protect the BBB viability from the harmful exposure to Tobacco Smoke}

The effect of TS exposure (equivalent to that generated by 5,20 , and 35 cigarettes/day $(5 \mathrm{C}, 20 \mathrm{C}, 35 \mathrm{C}$ ) respectively) on $\mathrm{BBB}$ integrity was evaluated fully established DIV-BBB [66-68] modules (Figure 4A). Sham-TSexposed modules were used as control. TS levels equivalent to $5 \mathrm{C}$ did not significantly impaired $\mathrm{BBB}$ integrity as demonstrated by TEER (Figure 4A left panel) and Adenylate kinase (AK) release measurements (Figure $4 \mathrm{~B}$ ). In contrast, exposure to higher TS levels (20 and $35 \mathrm{C}$ ) resulted in rapid and dose-dependent loss of $\mathrm{BBB}$ integrity, which was accompanied by a significant increase of AK release when compared to controls, and to the release of $\mathrm{AK}$ that followed the exposure to a low level of TS (Figure 4A and 4B). We assessed the protective efficacy of antioxidant vitamins against the $\mathrm{BBB}$ exposure to TS levels equivalent to 20C/day. BBB integrity was partially protected against TS exposure-related damage by vitamin $\mathrm{E}$ and $\mathrm{C}$ as demonstrated by TEER (Figure 4C) and AK release (Figure 4D) measurements. The independent administration of these substances 


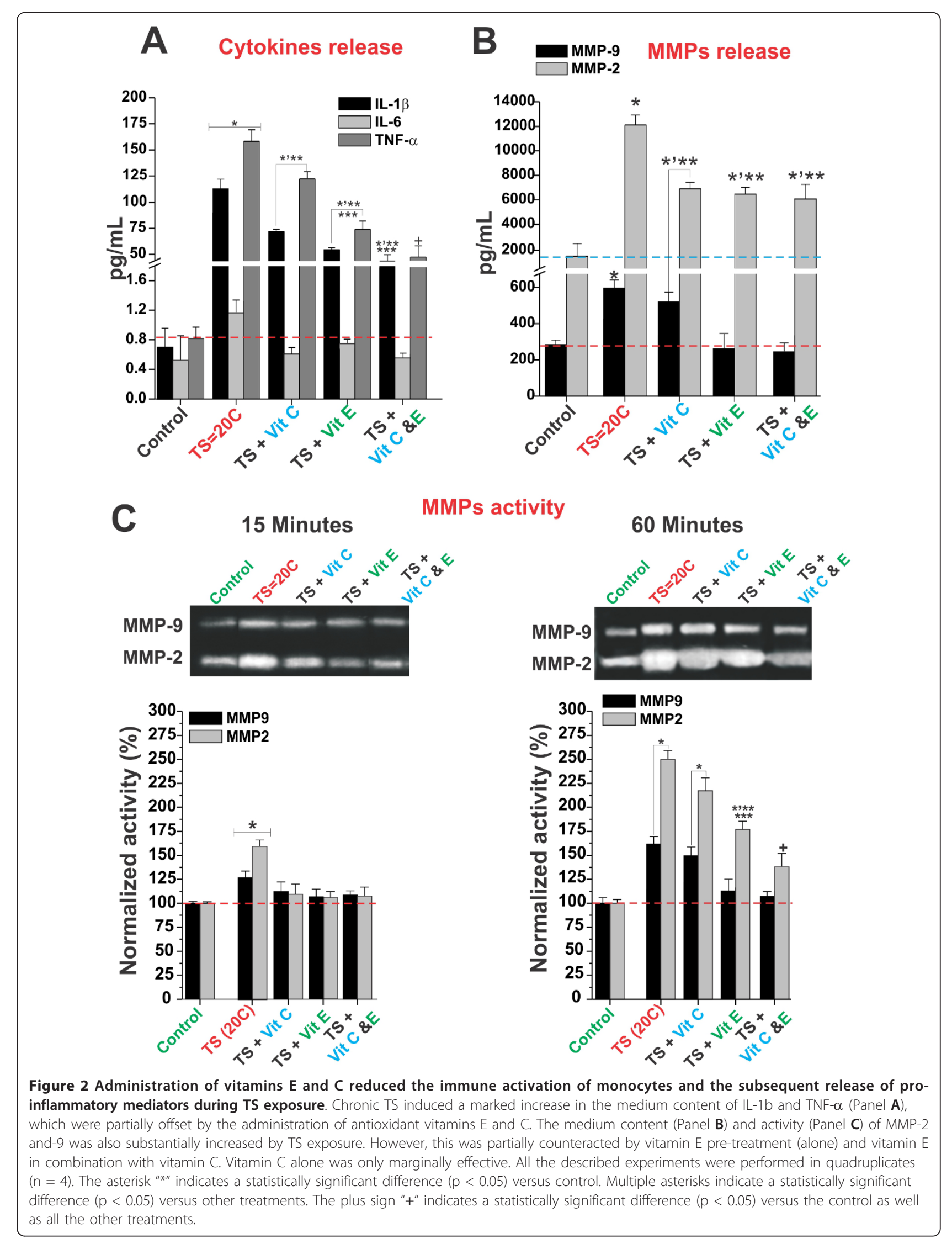




\section{A}
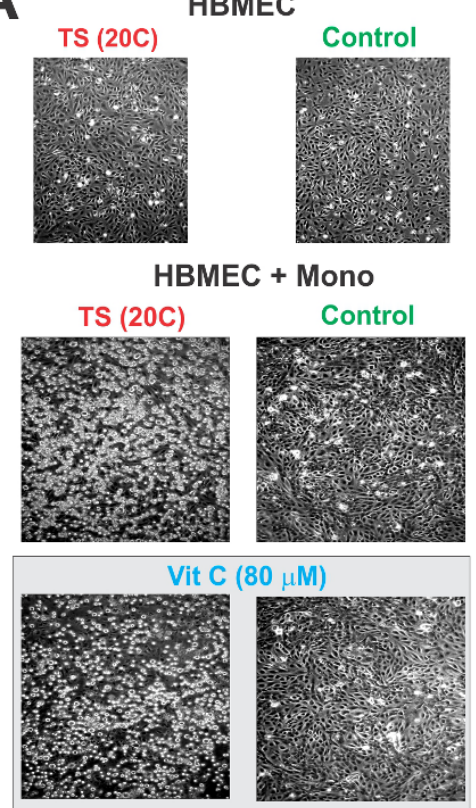

Vit $\mathrm{E}(40 \mu \mathrm{M})$
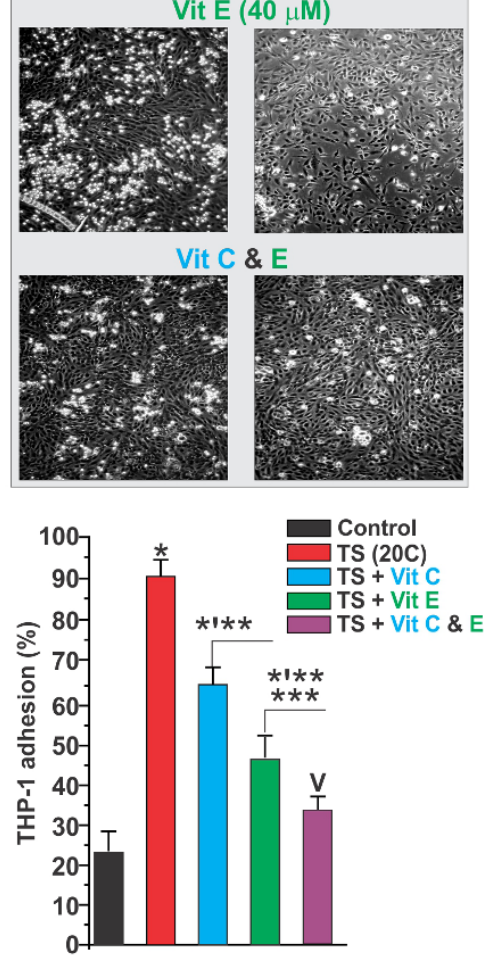
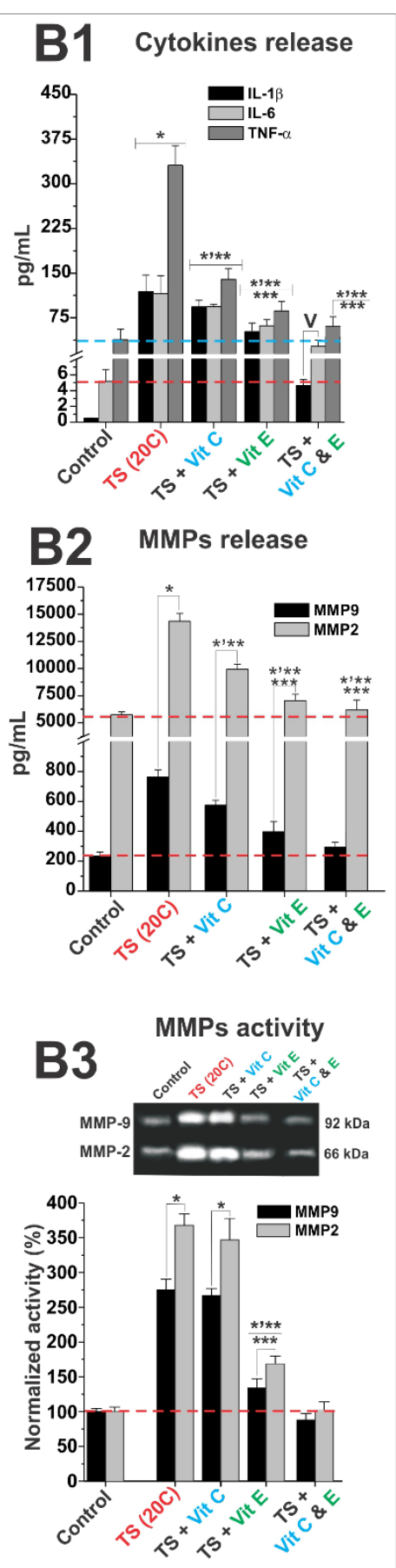

Figure 3 Antioxidant vitamins reduced the synergistic pro-inflammatory activation on HBMEC in presence of THP-1 cells during TS exposure. Visual inspection and quantification of adherent monocytes showed a dramatic increase in the number of monocyte-endothelial bonded cells following TS exposure (Panel A). Leukocyte-endothelial interactions during TS exposure were prevented by pre-treatment with physiological concentrations of vitamins $\mathrm{E}$ and (to a lesser extent). Analysis of the medium content showed that pre-treatment with antioxidant vitamins tested herein also reduced the release of IL-1 $\beta, \mathrm{IL}-6$ and TNF- $\alpha$ (Panel B1), that of MMP-2 and MMP-9 (Panel B2) and also reduced the MMP-2 and -9 activation (Panel B3). Note that the anti-inflammatory protection provided by pre-treatment with vitamin $\mathrm{E}$ alone and that of vitamin E and C combined, was significantly more effective (by magnitude and duration) than that of vitamin $C$ alone. All the described experiments were performed in quadruplicates $(n=4)$. The asterisk "**" indicates a statistically significant difference $(p<0.05)$ versus control. Multiple asterisks indicate a statistically significant difference $(p<0.05)$ versus other treatments. The plus sign "V" indicates a statistically significant difference $(p<0.05)$ versus the control as well as all the other treatments. 


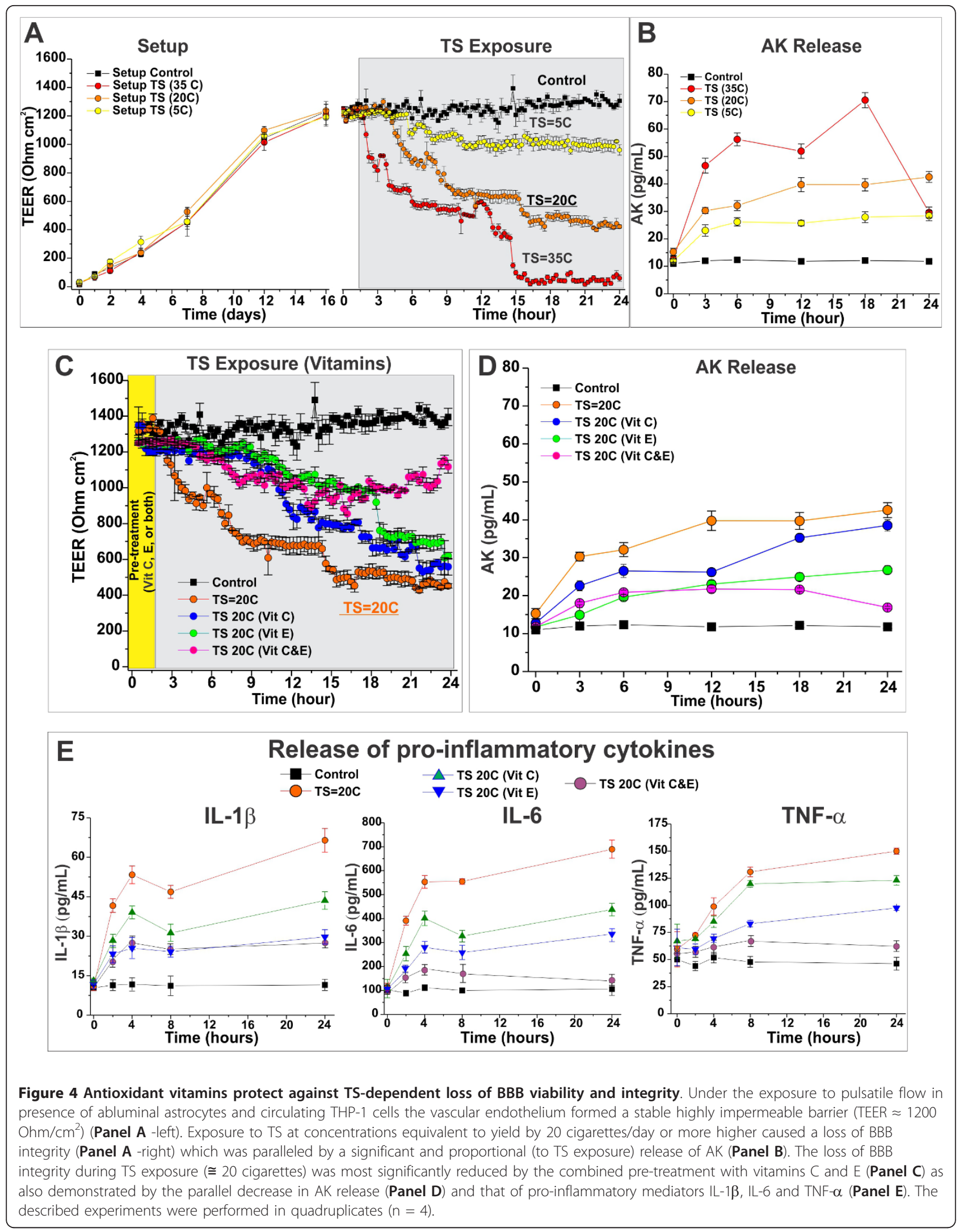


resulted in a delayed and a less severe loss of $\mathrm{BBB}$ viability. Note that the co-administrations of these vitamins provided the most significant protection. In addition to $\mathrm{BBB}$ deterioration during TS exposure, the analysis of the media samples showed a statistically significant increase in the levels of IL-1 $\beta$, IL-6, and TNF- $\alpha$ (Figure $4 \mathrm{E})$. Administration of antioxidant vitamins significantly reduced the TS-induced release of these pro-inflammatory cytokines with the combo approach being the most effective.

\section{Hydrogen peroxide impairs BBB integrity: Protective role of antioxidant vitamins}

The effect of hydrogen peroxide $\left(\mathrm{H}_{2} \mathrm{O}_{2}\right.$, one of the many redox active substances contained in cigarette smoke; 2$4 \mu \mathrm{M} \mathrm{H}_{2} \mathrm{O}_{2} / \mathrm{mg}$ of $\left.\operatorname{tar}[69,70]\right)$ exposure on BBB integrity was assessed in the DIV-BBB. Three levels of $\mathrm{H}_{2} \mathrm{O}_{2}$ exposure comparable to that yield by 5,20 , and $352 \mathrm{R} 24$ research cigarettes $(55,220$, and $385 \mu \mathrm{M}$ respectively) were tested. Sham- $\mathrm{H}_{2} \mathrm{O}_{2}$-exposed modules were used as control. Exposure to $\mathrm{H}_{2} \mathrm{O}_{2}$ equivalent to that generated by 5 cigarettes $(55 \mu \mathrm{M})$ did not affect BBB integrity (Figure 5A-right panel) as demonstrated by TEER measurements. In contrast, exposure to higher levels of $\mathrm{H}_{2} \mathrm{O}_{2}$ (110 and $220 \mu \mathrm{M}$ respectively) resulted in rapid and dose-dependent loss of BBB integrity. Pre-treatment with vitamin $\mathrm{E}$ and $\mathrm{C}$ provided only a partial protection against oxidative damage to the $\mathrm{BBB}$ (Figure $5 \mathrm{~B}$ ). Note that the efficacy of the antioxidative protection was assessed against the effect of the highest of the 3 levels of $\mathrm{H}_{2} \mathrm{O}_{2}$ exposure $(220 \mu \mathrm{M})$. Co-administration of vitamins $\mathrm{C}$ and $\mathrm{E}$ fully prevented the loss of $\mathrm{BBB}$ integrity and viability.

\section{Tobacco smoke can impair BBB viability through alteration in nitric oxide bioavailability}

NO release by TS and by the vascular endothelium was assessed in real time by amperometric determination through electrode(s) in contact with the luminal and the abluminal compartments of the DIV-BBB modules. We determined a sudden and transient increase in the medium levels of NO (Figure 6A) in BBB modules exposed to TS versus sham systems, which correlated with the concentration of TS $(0.5,2.0,3.5$ cigarettes/hour for 1 hour yielded 40, 60 and $100 \mathrm{p} / \mathrm{Amp}$ NO peaks respectively). NO started declining immediately after reaching the peak level. However, the NO decline was negligible in DIV-BBB modules pre-treated with antioxidant vitamins $C$ and $E$.

During the recovery time (in the absence of TS) we observed a diametric decrease of $\mathrm{NO}$, which also correlated with the concentration of TS to which the corresponding $\mathrm{BBB}$ modules were initially exposed (Figure $6 \mathrm{~A})$. NO remained below the baseline level for $\approx 23$ hours before returning to normal. Pre-treatment with vitamins $C$ and $E$ did not prevent the reduction of $\mathrm{NO}$ bioavailability nor accelerated the return to a baseline level (Figure 6B).

\section{Tobacco smoke can alter the normal BBB bioenergetic metabolism: role of antioxidant vitamins}

Under normal physiological conditions BBB endothelial cells are characterized by a predominant oxygendepended bioenergetic metabolism (aerobic) [66,71]. The increased demand for reducing equivalents (e.g., $\mathrm{NADH}, \mathrm{FADH}_{2}$, etc.; normally utilized during oxidative respiration) to neutralize the reactive oxidative species from TS can cause metabolic alterations in the BBB endothelium [71]. As shown in Figure 7A (left panel) glucose consumption and lactate production levels were stable during the pre-TS phase treatment with a metabolic index (ratio between lactate production and glucose consumption) $\cong 1$ (Figure $7 \mathrm{~A}$ right panel). Administration of vitamins $\mathrm{C}$ and $\mathrm{E}$ at physiological concentrations ( $80 \mu \mathrm{M}$ and $40 \mu \mathrm{M}$ respectively) did not alter the metabolic behaviour of the BBB. However, exposure to TS (cycles of chronic exposure: every other hour for 12 hours/day) caused a decrease in glucose consumption (see Figure 7B left panel) and an unparalleled increase in lactate production, demonstrating a shift toward predominantly anaerobic bioenergetic metabolism (metabolic index $\cong 0.7$; see Figure $7 \mathrm{~B}$ right panel). Co-administration of vitamins $C$ and $E$ gradually restored the bioenergetic metabolism of the BBB.

\section{Discussion}

The BBB maintains brain homeostasis and selectively excludes most blood-borne and xenobiotic substances from entering the brain, protecting it from systemic and exogenous influences [72,73]. Deterioration in BBB functions have been clearly shown to play a major role in the pathogenesis and progression of a steadily increasing number of neurological disorders such as multiple sclerosis, Alzheimer's disease, neoplasia, hypertension, dementia, epilepsy, infection, and trauma [74]. While the harmful effects of smoking on public health have been well demonstrated and detailed in many organs, the $\mathrm{BBB}$ has received much less attention despite the strong evidence for an association between tobacco smoke and vascular impairment. Recently published data [25] have shown that TS negatively affects vascular endothelial physiology and directly promotes the pro-inflammatory activation of $\mathrm{BBB}$ endothelium.

Many of the over 4000 components contained in TS are thought to facilitate the development of a proatherosclerotic environment [25,28,75-77] by triggering a complex pro-inflammatory response. This is mediated by the recruitment of leukocytes through cytokine signalling (e. 


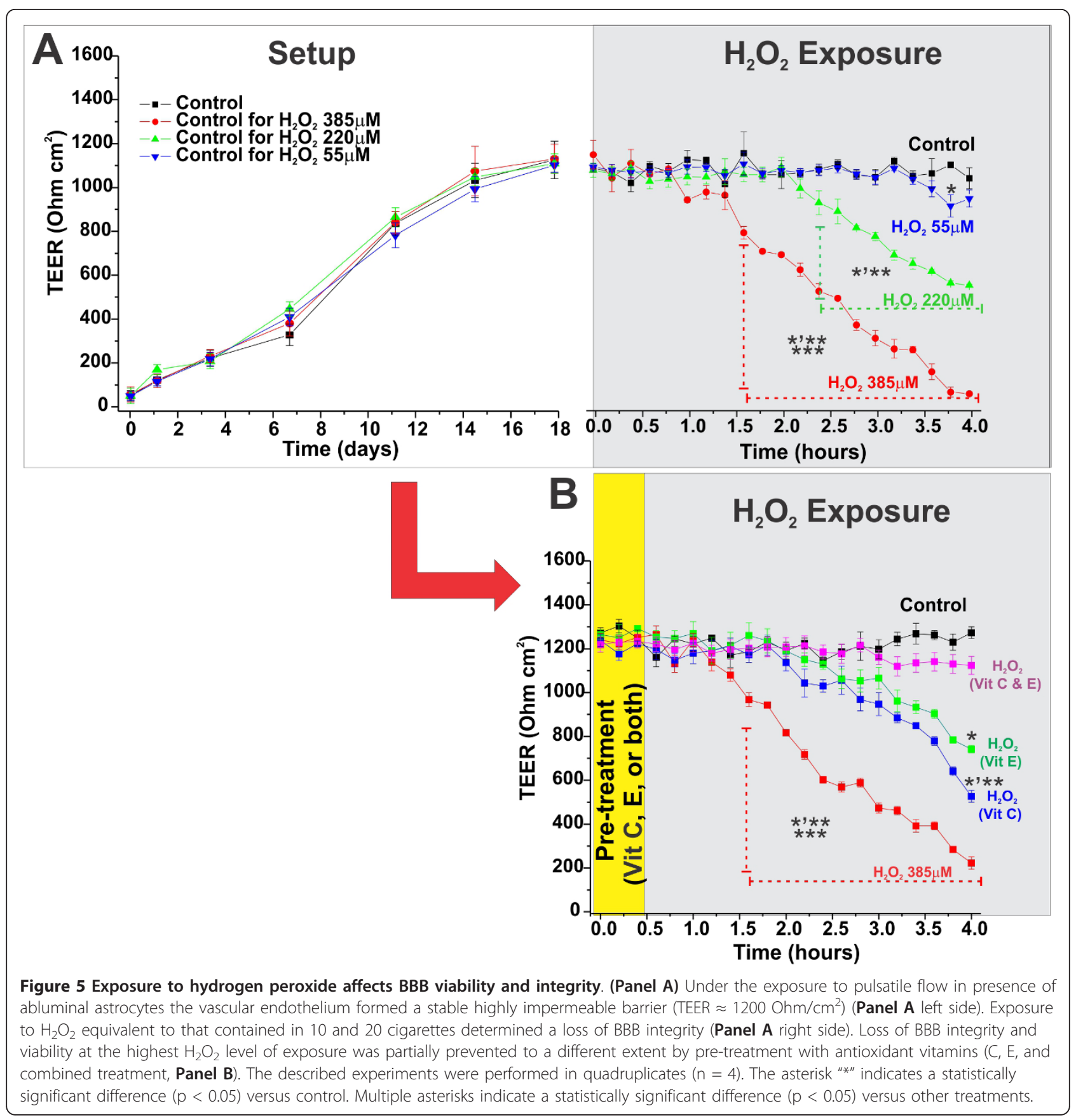

g., IL-2, IL-4, IL-6, IL-8, INF- $\gamma$ and GM-CSF), matrix metalloproteinase upregulation (e.g., MMP-1, MMP-8, and MMP-9), and by promoting the adherence of monocytes to the endothelial wall $[25,78]$.

TS's status as a powerful pro-inflammatory agent is suggested by the observation of elevated levels of white blood cells, primarily neutrophils and monocytes, in smokers [79]. Elevated C-reactive protein (CRP) levels caused by TS promotes endothelial dysfunction by lowering the production of $\mathrm{NO}$ and diminishing its bioactivity [80], thereby limiting the smoker's ability to vasodilate via NO release.

One well accepted yet poorly understood mechanism by which smoking can directly hamper BBB viability and function relays upon oxidative stress caused by the many highly reactive oxygen species and free radicals of which TS is highly enriched. The gas-phase of tobacco smoke alone is a complex mixture of high concentrations of ROS and free radicals (approximately one quadrillion radicals per puff [81]). This represents an 

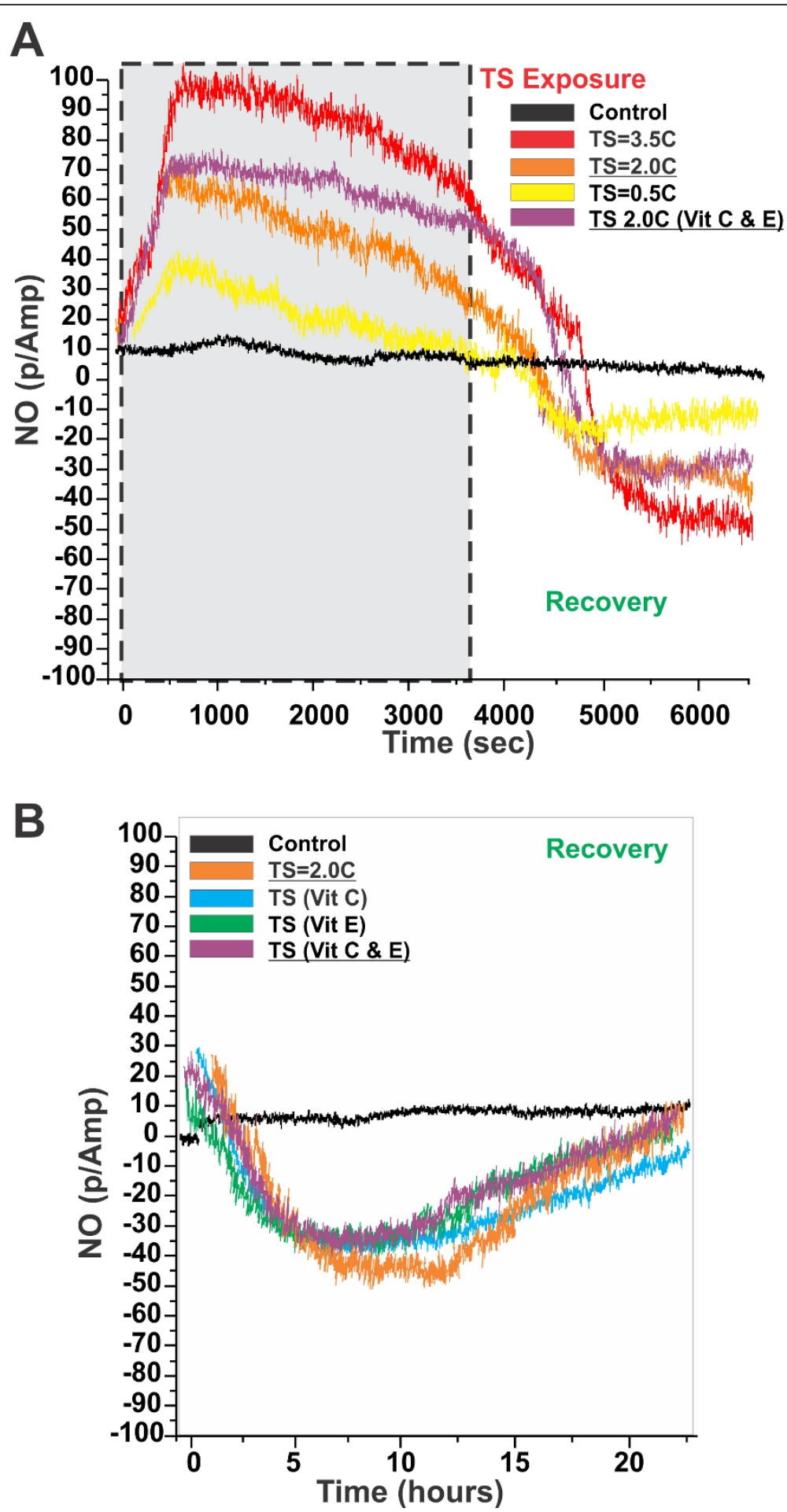

Figure 6 Amperometric determination of NO during and after TS exposure. (Panel A) Note the transient surge in the medium levels of NO immediately after TS exposure followed by a steady decline that brought the NO to below baseline levels during the recovery time. (Panel B) Pre-treatment with vitamins $C$ and $E$ did not prevent the reduction of NO bioavailability nor accelerated the return to a baseline level but reduced the NO decline during the initial phase of TS exposure (Panel A -right). Please note that reading conversion of the NO sensors was $\cong$ $1.5 \mathrm{pA} / \mathrm{nM} \pm 3 \%$. The described experiments were performed in quadruplicates $(n=4)$. 


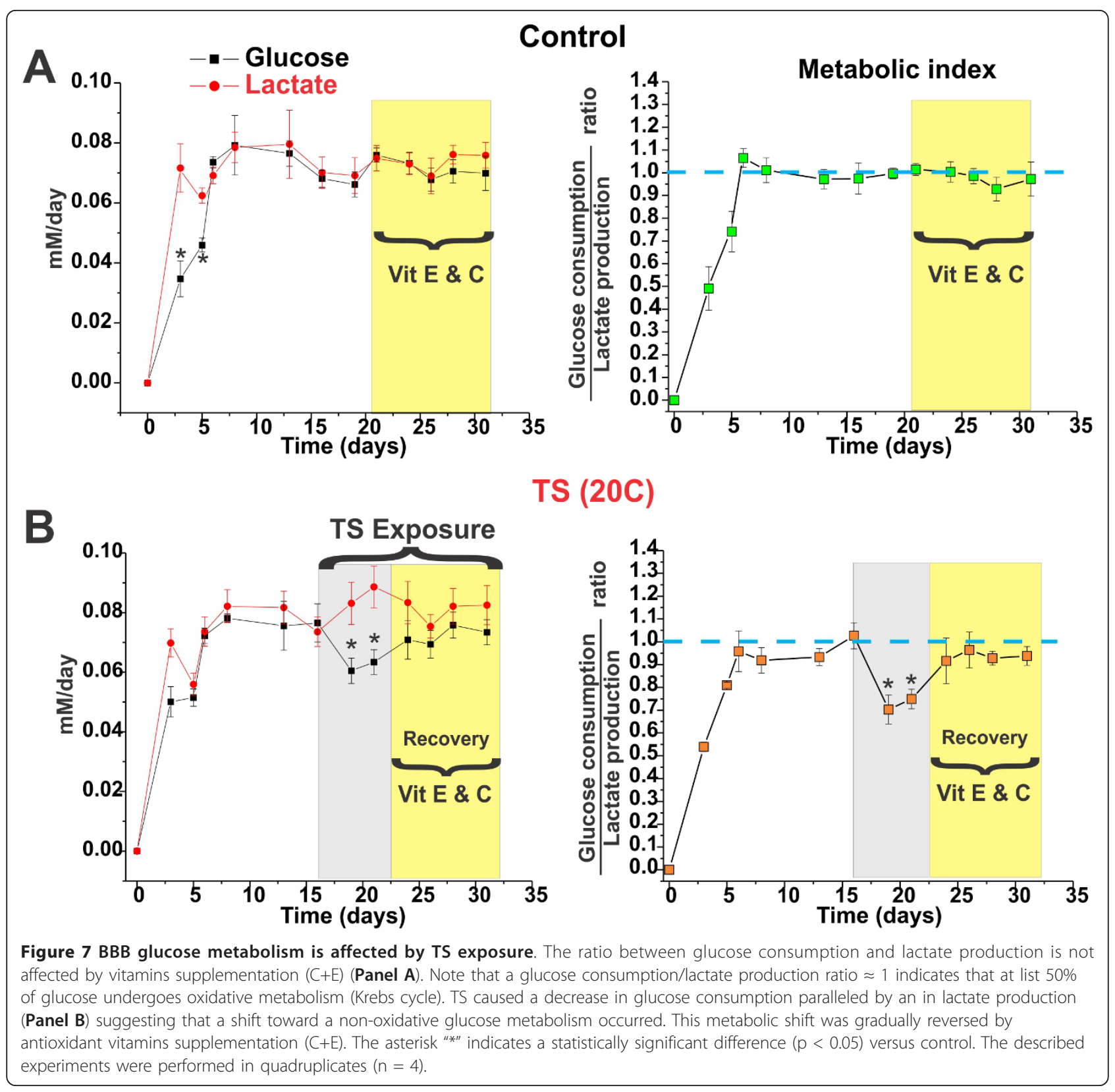

exorbitant load of oxidant to body tissues which can lead to BBB breakdown by oxidative damage, tight junction (TJ) modification, and matrix metalloproteinases (MMP) activation [32]. The results presented herein suggest that antioxidant vitamins may provide an effective shielding against oxidative stress thus, protecting the BBB during TS exposure.

Our data have shown that the administration of physiological concentration of vitamin $\mathrm{E}$ and/or $\mathrm{C}$ reduced the $\mathrm{BBB}$ endothelial pro-inflammatory activation solicited by TS exposure (see Figure 1). While the precise mechanism/s by which TS triggers an immune vascular response at the $\mathrm{BBB}$ cannot be determined from these experiments, our data strongly suggest that: 1) the imbalance between tissue/plasma concentrations of antioxidants and reactive oxygen species caused by TS played a major role in the process; 2) this can be partially prevented by administration of antioxidant vitamins.

The BBB endothelium is not the only tissue affected by TS. Our data also showed that TS directly activated monocytes which resulted in the release of IL-1 $\beta$ and TNF- $\alpha$ and MMPs (see Figure 2). We also observed a time dependent increase in the activity of MMP-2 and MMP-9 which initiated as early as 15 minutes of TS exposure and increased substantially after 60 minutes. 
The increased activity of matrix metalloproteinases reflected the continuous release of these enzymes during TS exposure suggesting an ongoing pro-inflammatory stimulation of the cells. Similar to what observed in BBB ECs cultures, pre-treatment with antioxidant vitamins reduced monocytes pro-inflammatory activation by TS.

In this study we used a final concentration of vitamin $\mathrm{C}(80 \mu \mathrm{M})$ equivalent to that found independently of gender in healthy non-smoker subject (35.3-107.1 $\mu \mathrm{M}$; 6.2-18.8 $\mathrm{mg} / \mathrm{L}$ ) according to literature data [82]. Not surprisingly the anti-inflammatory activity of vitamin C was limited to the initial 15 minutes of TS exposure. Vitamin $C$ is an hydrophilic reducing agent making it the first line of defense against ROS and the first to be consumed in the process. Therefore, it very likely that higher concentrations and/or a sustained supplementation of vitamin $C$ are necessary to maintain a protective effect for a longer period of time. This is agreement with the decision of Food and Nutrition Board of the National Academy of Sciences to raise the RDA of vitamin C for smokers to over $200 \mathrm{mg} /$ day $(\cong 160 \mu \mathrm{M} / \mathrm{l}$ cconsidering an estimated $70 \%$ absorption which decreases as intake increases) versus the recommended $90 \mathrm{mg} /$ day for non-smokers. This help counteracting vitamin $\mathrm{C}$ depletion caused by TS-derived ROS over time.

On the other hand, when vitamin $\mathrm{C}$ was co-administered with vitamin $\mathrm{E}$ (a powerful fat soluble reducing agent and the primary antioxidant present in the lipidrich cell membranes; see also Figure 3) the protective effect was significantly enhanced both in efficacy and duration. The interaction between vitamins $E$ and $C$ has been recognized and extensively studied showing an ascorbate-mediated regeneration of oxidized membrane alpha-tocopherol back to its reduced form. A process that extends the protective effect of vitamin $\mathrm{E}$ against oxidative stress [83].

Whether ROS can directly hamper BBB viability was also clearly demonstrated. Our results showed a time and dose dependent loss of BBB viability when in the absence of physiological antioxidants protection the DIV-BBB modules were exposed to $\mathrm{H}_{2} \mathrm{O}_{2}$ levels comparable to those a chronic smoker is routinely exposed (see Figure 5). Our findings are in agreement with studies by others showing that plasma antioxidant vitamins (especially ascorbic acid) levels in chronic smokers are significant decreased due to accelerated turnover in response to TS-evoked oxidative stress [51]. This is also in agreement with the fact that administration of antioxidant vitamins $C$ and $E$ (particularly when combined) prevented the loss of $B B B$ integrity.

Not surprisingly, direct BBB exposure to TS showed similar results. We observed a similar time and dose dependent pattern of BBB impairment (see Figure 4A), which was paralleled by the release of adenylate kinase (a well-established marker of cell damage; see Figure $4 \mathrm{~B})$. This suggests that the increased paracellular permeability is not exclusively dependent (at least in the short term) on the exposure to nicotine [84] contained in TS but also to cell damage caused by ROS. This hypothesis is supported by the fact that pre-treatment with antioxidant vitamins significantly reduced the loss of $\mathrm{BBB}$ viability during TS exposure (see Figure $4 \mathrm{C}$ ). This was accompanied by a similar decreased in the release of AK (see Figure 4D) and that of pro-inflammatory cytokines (see Figure 4E). The latter is also in agreement with previous studies showing that vitamin $C$ plays an important (yet not fully understood) role in the modulation of cytokines release as well as other immune surveillance activities [57].

Another mechanism through which tobacco smoke can impair $\mathrm{BBB}$ viability is through the alteration of nitric oxide bioavailability. NO is a molecular mediator involved in a variety of physiologic and pathological processes. Three isoforms of NOS have been described: neuronal NOS (nNOS), endothelial (eNOS) and inducible or immunological NOS (iNOS). Vascular endothelial cells generate small bursts of NO from $\mathrm{L}$-arginine via increase in intracellular $\mathrm{Ca}^{2+}$ through a calcium-dependent constitutive NO synthase (eNOS). In contrast, iNOS induced in pathological/inflammatory state is Caindependent manner and releases NO continuously in large amounts. Our data showed a sudden burst in NO (see Figure 6A) immediately after the initial exposure to tobacco smoke. Consequent to the sudden raise of $\mathrm{NO}$ we observed a steady decline on NO levels which suggests a rapid reaction of NO with other TS-released ROS and its conversion in peroxynitrite (ONOO-) [85]. This hypothesis is in agreement with the fact that NO decline was prevented by pre-administration of antioxidant vitamins, which neutralized the ROS contained in TS. This being the case, it is possible that antioxidant treatments may indeed prolong the initial NO-dependent vasodilatation experience by smokers during TS exposure.

By contrast, during the recovery time (in the absence of TS) NO dropped below the baseline level. The magnitude of this decline appeared to be proportional to the amount of TS to which the corresponding BBB modules were previously exposed. While the precise mechanisms by which TS affected NO bioavailability cannot be entirely determined from these experiments, some inferences can be still derived. Nicotine contained in TS has been shown to inhibit eNOS activity, thus decreasing the constitutive level of NO release by the vascular endothelium $[86,87]$. As shown in Figure 6B pre-treatment with antioxidant vitamins did not affect the decline of NO during the recovery phase. This supports 
the hypothesis that perhaps nicotine rather than ROS are responsible for the observed decline of $\mathrm{NO}$ during this phase leading to vasoconstriction and aggravating the vascular impairment of the brain $[88,89]$.

Tobacco smoking has also been associated with impairments of glucose metabolism and glycemic regulation [90]. Our data have clearly shown that TS exposure determined a decrease in glucose consumption (Figure 7B left panel), paralleled by an increase in lactate production. This is indicative of a potential change in the $\mathrm{BBB}$ bioenergetic behaviour toward a more predominant anaerobic metabolism (see Figure 7B right panel). The mechanisms through which TS affect glucose metabolism may be related to free radicals and other ROS contained in tobacco smoke [11]. In vivo, this effect can be further exacerbated by the carbon monoxide $(\mathrm{CO})$ also contained in tobacco smoke. $\mathrm{CO}$ through binding to hemoglobin, myoglobin and mitochondrial cytochrome oxidase [91] can cause a relatively prolonged impairment of glucose oxidative metabolism and a decrease in glucose utilization $[92,93]$

One way through which $\mathrm{BBB}$ endothelial cells can try to counteract the increased levels of ROS is through the generation of reductant equivalents such as glutathione peroxidase (of the principal antioxidant defense enzymes). Generation of glutathione peroxidase requires oxidized glutathione to be reduced by glutathione reductase using NADPH generated in the pentose phosphate pathway (also called the phosphogluconate pathway). This process generates NADPH (oxidative phase) and pentoses (5-carbon sugars; non-oxidative synthesis) [11]. A shift toward the pentose phosphate pathway to compensate for the excess of ROS would explain the reduced glucose consumption we observed during TS exposure.

Furthermore, BBB endothelial cells could also use the Krebs cycle reducing agents (normally utilized to sustain the energy-producing pathway based on oxidative phosphorylation) to counteract TS-derived ROS. This would leave the cellular mitochondria underequipped to sustain the oxidative glucose metabolism and would explain the increased lactate production also observed during TS exposure. This hypothesis is supported by our data which showed that administration of antioxidant vitamins $C$ and $E$ gradually restore the normal bioenergetic metabolism of the BBB (see Figure 7B) [11,94]. However, a more specific and detailed study will be necessary to confirm this hypothesis and unravel the underlining mechanism/s.

\section{Conclusion}

Our data indicate that loss of endothelial viability as well as BBB function and integrity in vitro caused by TS exposure can be significantly reduced by pre-treatment with physiologic concentrations of $\alpha$-tocopherol and ascorbic acid. These antioxidant vitamins may act synergistically in preventing oxidative damage and proinflammatory stimulation induced by tobacco smoking exposure, thereby reducing TS toxicity at the BBB level.

\section{Study limitations}

In vitro toxicology studies of tobacco and tobacco smoke have been used widely used to assess the toxicologic impact of tobacco product. However, there are limitations with respect to the generality of the findings inherited in such studies which reflect the inability of any in vitro model to fully recapitulate the biological and physiological make up a living organism. In this study we used an artificial vascular system to assess the effect of TS exposure on the BBB and whether administration of vitamin $\mathrm{C}$ and/or E can reduce TS toxicity. However, our model cannot reproduce for example, the effect of hepatic clearance and peripheral metabolism on the concentration of TS components to which the BBB and the immune system are exposed. This can lead to a relative over-exposure of the BBB and its constituents (including circulating monocytes) to TS thus, exaggerating its acute harmful effects. In vitro studies on TS toxicity (such the one reported in here) more likely reflect the impact of chronic smoking over a long period of time (in general several years) were cumulative harmful effect builds up overtime.

\section{Methods}

\section{TS Preparation}

Concentrated smoke solution was prepared from $2 \mathrm{R} 4 \mathrm{~F}$ research cigarettes, which are high nicotine, high tar, filter cigarettes (University of Kentucky). The cigarettes were smoked using a Borgwaldt RM2 apparatus according to ISO determination parameters. These require a puff volume for each cigarette of $35 \mathrm{~mL}$ with duration of $2 \mathrm{~s}$ at intervals of $60 \mathrm{~s}$, with an airflow surrounding the cigarette of $\cong 200 \pm 30 \mathrm{~mm} / \mathrm{s}$. This protocol resulted in approximately 8 puffs/cigarette. Stocks of smoke solution were obtained by drowning (using a vacuum pump) the mainstream smoke from 40 cigarettes through $10 \mathrm{ml}$ of sterile phosphate buffered saline (PBS) (abbreviated TS1). Tobacco smoke was then quantified as cigarette/ $\mathrm{mL}(\mathrm{c} / \mathrm{mL})$. The resulting concentration of the stoke solutions was $\cong 4 \mathrm{c} / \mathrm{mL}$. The stock solutions were used immediately after preparation. Note that cells were put in contact with the soluble smoke extract in cycles of 120 minutes for a total period of 12 hours/day where each cycle was divided as described: 0-15 minutes (vitamin pre-treatment or nothing); 15-75 minutes (TS exposure or nothing if control), 75-120 exchange with TSfree medium (including controls). Each set of cycles was designed to deliver exposure to TS equivalent to that 
yielded by $\cong 20$ cigarettes per day or $\cong 1.67 \mathrm{c} /$ cycle . Media samples (TS and TS-free) were collected throughout the cycles and stored for analysis.

\section{Hydrogen peroxide preparation}

Hydrogen peroxide solution (PERDROGEN ${ }^{\circledR} 30 \% \mathrm{H}_{2} \mathrm{O}_{2}$ ) was purchased from Sigma-Aldrich (St. Louis, MO 63178; cat\# 31642) and diluted to achieve the appropriate final experimental concentrations $(55,220$, and 385 $\mu \mathrm{M}$ respectively which are comparable to that yield by 5 , 20, and $352 \mathrm{R} 24$ research cigarettes; $2-4 \mu \mathrm{M} / \mathrm{mg}$ of tar $[69,70])$. Dulbecco's Phosphate Buffered Saline (Sigma-Aldrich, St. Louis, MO 63178; cat\# D4031) containing $36 \mathrm{mg}$ sodium pyruvate, $50 \mathrm{mg}$ streptomycin sulfate, $100 \mathrm{mg}$ kanamycin monosulfate, $1000 \mathrm{mg}$ glucose/ $\mathrm{L}$ and $\mathrm{CaCl}_{2}$ adjusted to a $\mathrm{pH} \cong 7.5$ was used to make dilutions of hydrogen peroxide. The solutions were prepared fresh before the experiment and maintained at $37^{\circ}$ C.

\section{Ascorbic acid and $\alpha$-tocopherol preparation}

$\alpha$-tocopherol (vitamin E, cat\# AC42103-1000) and ascorbic acid (vitamin C, cat\# AC40147-1000), were purchased from Fischer Scientific Pittsburgh, PA. 43.07 $\mathrm{mg}$ of $\alpha$-tocopherol were dissolved in $10 \mathrm{~mL}$ of ethanol yielding a stock solution of $10 \mathrm{mM}$. The experimental concentration of $\alpha$-tocopherol $(40 \mu \mathrm{M})$ was achieved by diluting $4 \mu \mathrm{L}$ of the stock solution in $1 \mathrm{~mL}$ of the specific growth medium. Ascorbic acid (35.22 mg) was instead dissolved in $10 \mathrm{~mL}$ of PBS yielding a stock solution of $20 \mathrm{mM}$. Final experimental concentration of ascorbic acid $(80 \mu \mathrm{M})$ was achieved by diluting $4 \mu \mathrm{L}$ of the stock solution in $1 \mathrm{~mL}$ of the specific growth medium. In the described experiments cells were pre-treated with vitamin $C$ and $E$ (at a final concentration of $80 \mu \mathrm{M}$ and $40 \mu \mathrm{M}$ respectively) prior exposure to soluble tobacco smoke extract.

\section{Cell Culture}

Normal human brain microvascular endothelial cells (HBMEC, cat\# 1000), and human astrocytes (HA, cat\# 1800) were purchased from ScienCell Research Laboratories, San Diego, CA 92121. HBMEC were expanded in $75 \mathrm{~cm}^{2}$ flasks pre-coated with fibronectin $\left(3 \mu \mathrm{g} / \mathrm{cm}^{2}\right)$ using Endothelial Basal Medium MCDB 105 (Sigma, Cat\# M6395) containing 10\% human AB serum (SIGMA, Cat\# S-7148), $15 \mathrm{mg} / 100 \mathrm{ml}$ of endothelial cell growth supplement (ECGS, Cat.\# 1052), 800 units/ml of heparin (Sigma, cat\# H3393), 100 units/ml penicillin G sodium and $100 \mathrm{mcg} / \mathrm{ml}$ streptomycin sulfate. Prior to use HBMEC were characterized by immunocytochemistry using sheep polyclonal antibodies that recognized the human Von Willebrand Factor Antigen VIII (vWF/Factor VIII, US biological, Swampscott, MA, cat\# F0016-13A).
HA were grown in Poly-d-Lysine pre-coated flasks (3 $\mu \mathrm{g} / \mathrm{cm}^{2}$ ) with Dulbecco's modified essential media (DMEM-F12) supplemented with $2 \mathrm{mM}$ glutamine, $5 \%$ fetal bovine serum (FBS), 100 units of sodium penicillin $\mathrm{G}$ per $\mathrm{ml}$, and $100 \mathrm{mcg}$ of streptomycin sulfate per $\mathrm{ml}$. To obtain a highly purified astrocytic population Cytosine arabinoside and L-leucine methyl ester (SigmaAldrich, MO, USA) were added [95] and HA cultures were agitated overnight at $37^{\circ} \mathrm{C}$. We used rabbit polyclonal antibodies specific for the glial cell marker glial fibrillary acidic protein (GFAP, Dako Corporation, Carpentaria, CA, USA) to assess the purity of the HA cultures which resulted $>95 \%$. Both endothelial cells and astrocytes were maintained at $37^{\circ} \mathrm{C}$ in a humidified atmosphere with $5 \% \mathrm{CO}_{2}$. Note that cells were not expanded for more than 2 cycles to minimize cell dedifferentiation.

The human monocytic leukemia cell line (THP-1, Cat\# TIB-202) was purchased from American Type Culture Collection (ATCC, Manassas, VA). THP-1 cells were grown at $37{ }^{\circ} \mathrm{C}$ in $95 \%$ air $-5 \% \mathrm{CO}_{2}$ in basal medium (ATCC-formulated RPMI-1640 Medium, Catalog No. 30-2001) plus $0.05 \mathrm{mM}$ 2-mercaptoethanol and $10 \%$ fetal bovine serum as specified by the vendor.

\section{DIV-BBB setup}

HBMEC and HA were cultured in a dynamic model of the blood-brain barrier (DIV-BBB) in polypropylene or on hollow fiber capillaries, as previously described (see Figure 8). Briefly, the luminal surface of the hollow fibers was pre-coated with $3 \mu \mathrm{g} / \mathrm{cm}^{2}$ fibronectin to allow HBMEC adhesion. The abluminal surface of the fibers was pre-coated with $3 \mu \mathrm{g} / \mathrm{cm}^{2}$ of poly-D-lysine to promote $\mathrm{HA}$ adhesion. HBMEC were first introduced into the luminal compartment and allowed to adhere for 3 hrs without pulsatile flow. To maximize HBMEC adhesion, the flow of medium was initiated in the abluminal compartment for $24 \mathrm{hrs}$, then switched to pass directly over the HBMEC in the luminal compartment at a low level shear stress $\left(2 \mathrm{dyne} / \mathrm{cm}^{2}\right)$ for another 24 hours. The shear stress was then raised to a constant value of 4 dyne $/ \mathrm{cm}^{2}$. HA were seeded on the abluminal surface of the fibers three days after HBMEC were loaded. Typically, two weeks of co-culture are required to establish a fully functional BBB with a TEER greater than $800 \Omega$ $\mathrm{cm}^{2}$ above the baseline (measured as TEER in a cell-free module).

\section{TEER measurement}

TEER measurement provides a rapid, simple evaluation of the integrity of the DIV-BBB. Our TEER measurement device was purchased from Flocel (Flocel Inc., Cleveland, $\mathrm{OH}$ 44103). This system utilizes electronic multiplexing to test multiple DIV-BBB modules in rapid 


\section{DIV-BBB system}

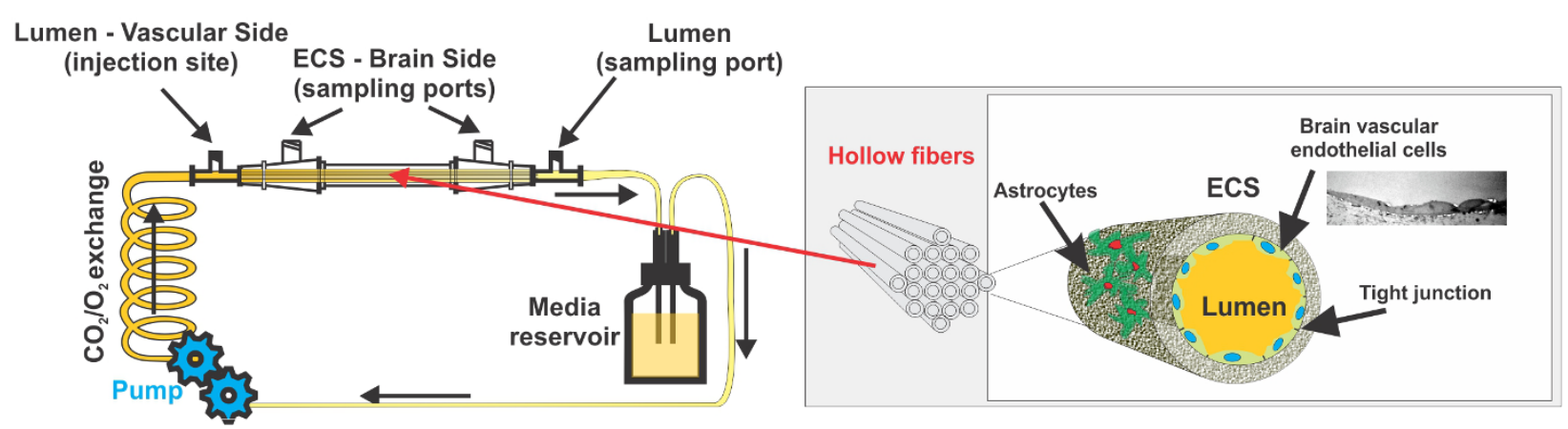

Figure 8 Schematic of a DIV-BBB module. A bundle of porous polypropylene hollow fibers is suspended in the DIV-BBB chamber. The artificial capillaries are in continuity with a medium source through a flow path consisting of gas-permeable silicon tubing. Ports positioned on either side of the module allow access to the luminal and abluminal compartments. Note how this artificial capillary system closely mimics the physiology of the BBB in situ.

succession and deliver data to a computer. Details on the core system are available on the website of the maker of the device (http://www.Flocel.com). We have previously verified that this method documents a strong inverse relationship between TEER and permeability across the EC monolayer in the DIV-BBB modules [66-68].

\section{Measurement of nitric oxide (NO)}

Changes in nitric oxide (NO) were measured by amperometric determination using an optically isolated multi-channel free radical analyser (World Precision Instruments, Sarasota, FL). The NO measuring probe is inserted into the lumen downstream from the hollow fiber apparatus and another probe in the ECS compartment. NO is detected as previously described [96,97]. The on-line changes in NO were continuously measured using a PC-driven system. Based on internal calibration reading conversion of the $\mathrm{NO}$ sensors was $\cong 1.5 \mathrm{pA} / \mathrm{nM}$ of NO. Max sensitivity $\cong 50 \mathrm{fA}$ according to the manufacturer.

\section{Measurement of cytokines and MMPs}

Samples of medium from the luminal compartment were centrifuged at 5,000 g for $5 \mathrm{~min}$ and stored at -20 ${ }^{\circ} \mathrm{C}$ until analysis. Levels of IL- 6 , IL-1 $\beta$, and TNF- $\alpha$ were measured by ELISA (cat\# IB39673 (IL-6); \# IB39654 (IL1ß; \# IB39699 (TNF- $\alpha$ ); IBL America, Minneapolis, MN) according to the manufacturer's protocols. MMP-2 and MMP-9 were also quantified by ELISA (cat\# QIA631EA (MMP-2) and QIA56-1EA (MMP-9); Calbiochem, San Diego, CA). Final calculation of cytokine levels (pg/ $\mathrm{mL}$ ) took into consideration time and volume of the luminal compartment according to the formula: $\left(\mathrm{V}_{\mathrm{t}} \mathrm{xC}_{\mathrm{c}}\right)$ $\left(\mathrm{V}_{\mathrm{n}} \mathrm{x} \mathrm{C}_{\mathrm{n}}\right)+\left(\mathrm{V}_{\text {total }} \mathrm{x} \mathrm{C}_{\mathrm{p}}\right) / \mathrm{T}_{\mathrm{c}}-\mathrm{T}_{\mathrm{p}}$, where $\mathrm{V}$ represents added volume of media $(\mathrm{mL})$; $\mathrm{C}$ refers to the concentration of a cytokine/MMP level $(\mathrm{pg} / \mathrm{mL}) ; \mathrm{T}$ is time of sampling (in fraction of days: ${ }_{\mathrm{c}}$ and $\mathrm{p}_{\mathrm{p}}$ indicate the current and previous samples, respectively; and ${ }_{n}$ represents cytokine values in the fresh medium added after each sampling.

\section{Flow cytometry (FACS) and data analysis}

TS-exposed and control endothelial cells were rinsed with PBS. Cells were then gently mixed with chelation buffer (1mM EDTA prepared in $\mathrm{Ca}^{2+} / \mathrm{Mg}^{2+}$ free PBS) using a pipette tip washed in FACS buffer. (PBS+0.5\% $\mathrm{BSA}+0.02 \% \mathrm{NaN}_{3}$ ) and resuspended to approx. 1 million cells $/ 100 \mu \mathrm{l}$. Cells were incubated with fluorescein diisothiocyanate conjugated anti-P-selectin, phycoerythrinconjugated anti-E-selectin, or alkaline phosphatases conjugated anti-VCAM-1 (respectively, cat.\#555524; \# 551144; \#551146; BD Biosciences, San Jose, CA) for 20 minutes in the dark. Unbound antibody was removed by several washes with FACS buffer. Cells were then resuspended in $200 \mu \mathrm{l}$ of FACS buffer/sample for analysis and data were calculated by Flow Jo 6.1.1 (Tree Star) for Mac OS X. THP-1 cell suspensions were similarly tested for CD45/CD14 (cat. \#340040; BD Biosciences).

\section{Matrix metalloproteinase activity}

Aliquots of medium from the luminal compartment were centrifuged at $14,000 \mathrm{~g}$ for $15 \mathrm{~min}$ at $4{ }^{\circ} \mathrm{C}$ and any cell pellet discarded. Total protein content of the medium was determined by Bradford assay. Gelatin zymography of electrophoresed medium samples was carried out on $7.5 \%$ polyacrylamide gels copolymerized with 2 g/L 90 Bloom Type A gelatin from porcine skin (Sigma). After electrophoresis, gels were washed in Triton X-100 $(2.5 \mathrm{~mL} / \mathrm{L})$ and incubated for $24 \mathrm{~h}\left(37^{\circ} \mathrm{C}\right)$ in enzyme buffer (50 mM Tris- $\mathrm{HCl}, \mathrm{pH} 7.5 ; 5 \mathrm{mM} \mathrm{CaCl2}$; 
$100 \mathrm{mM} \mathrm{NaCl} ; 1 \mathrm{mM} \mathrm{ZnCl} 2 ; 0.2 \mathrm{~g} / \mathrm{L} \mathrm{Brij}^{\circledR}-35 ; 2.5 \mathrm{~mL}$ Triton X-100; and $0.02 \mathrm{~g} / \mathrm{Lf} \mathrm{NaN} 3)$. Gels were stained with 0.5\% Coomassie Blue R-250. Lysis bands were measured densitometrically with an image analyzer.

\section{Statistical analysis}

For parametric variables (e.g., TEER levels, glucose consumption, lactate production, cytokines levels), differences between populations were analysed by ANOVA. $p$ values $<0.05$ were considered statistically significant. Bonferroni analysis was used to account for comparisons of multiple parameters among groups. For non-parametric indices (e.g. densitometries for zymogram), we used the Kruskal-Wallis test followed by Mann-Whitney U-test. We used four cartridges per data point. Based upon previous experiments, this number of cartridges provided sufficient power to demonstrate statistical significance.

\section{Acknowledgements}

This work was supported by NIH/NIDA R01-DA029121-01A1 and Alternative Research Development Foundation (A.R.D.F.) to Dr. Luca Cucullo.

\section{Author details \\ ${ }^{1}$ Cerebrovascular Research Department of Pulmonary Medicine, Cleveland Clinic, Cleveland, OH 44195 USA. ${ }^{2}$ Department of Cell Biology Department of Pulmonary Medicine, Cleveland Clinic, Cleveland, OH 44195 USA. ${ }^{3}$ Department of Pulmonary Medicine, Cleveland Clinic, Cleveland, $\mathrm{OH} 44195$ USA. ${ }^{4}$ Case Western Reserve University, Cleveland, OH 44106 USA. ${ }^{5}$ Pharmaceutical Sciences, Texas Tech University Health Sciences Center, Amarillo, TX 79106 USA.}

\section{Authors' contributions}

$\mathrm{MH}$ established all the cell cultures, the DIV-BBB modules and the static coculture systems. He also performed all the experiments described in this manuscript including the immunoassays and zymographies. PM provided his expertise in data analysis and collaborated with LC in the draft of the manuscript. WT participated in the data analysis and provided substantial support in the editing of the manuscript. LC conceived and supervised the study, elaborated its design and the experimental procedures and drafted the manuscript. All authors have read and approved the final manuscript.

\section{Disclosure/Conflict Of Interest}

Dr. Cucullo has reported the following financial relationships with the companies listed below.

Equity: Dr. Cucullo owns stocks in Flocel Inc.

Received: 11 June 2011 Accepted: 24 September 2011

Published: 24 September 2011

\section{References}

1. Adams MR, Jessup W, Celermajer DS: Cigarette smoking is associated with increased human monocyte adhesion to endothelial cells: reversibility with oral L-arginine but not vitamin C. J Am Coll Cardiol 1997, 29:491-497.

2. Brennan JA, Boyle JO, Koch WM, Goodman SN, Hruban RH, Eby YJ, Couch MJ, Forastiere AA, Sidransky D: Association between cigarette smoking and mutation of the p53 gene in squamous-cell carcinoma of the head and neck. N Engl J Med 1995, 332:712-717.

3. Chen HW, Chien ML, Chaung YH, Lii CK, Wang TS: Extracts from cigarette smoke induce DNA damage and cell adhesion molecule expression through different pathways. Chem Biol Interact 2004, 150:233-241.

4. Davis JW: Some acute effects of smoking on endothelial cells and platelets. Adv Exp Med Biol 1990, 273:107-118.
5. Freed BM, Ouyang Y, McCue JM: Mechanisms of altered transcription by cigarette smoke. Toxicol Sci 2001, 59:1-2.

6. Freeman DJ, Packard CJ: Smoking and plasma lipoprotein metabolism. Clin Sci (Lond) 1995, 89:333-342.

7. Henningfield JE, Stapleton JM, Benowitz NL, Grayson RF, London ED: Higher levels of nicotine in arterial than in venous blood after cigarette smoking. Drug Alcohol Depend 1993, 33:23-29.

8. Li XY, Rahman I, Donaldson K, MacNee W: Mechanisms of cigarette smoke induced increased airspace permeability. Thorax 1996, 51:465-471.

9. Morrison D, Rahman I, Lannan S, MacNee W: Epithelial permeability, inflammation, and oxidant stress in the air spaces of smokers. Am J Respir Crit Care Med 1999, 159:473-479.

10. Nagy J, Demaster EG, Wittmann I, Shultz P, Raij L: Induction of endothelial cell injury by cigarette smoke. Endothelium 1997, 5:251-263.

11. Noronha-Dutra AA, Epperlein MM, Woolf N: Effect of cigarette smoking on cultured human endothelial cells. Cardiovasc Res 1993, 27:774-778.

12. Raij $L$, Demaster $E G$, Jaimes $E A$ : Cigarette smoke-induced endothelium dysfunction: role of superoxide anion. J Hypertens 2001, 19:891-897.

13. Tsuchiya M, Asada A, Kasahara E, Sato EF, Shindo M, Inoue M: Smoking a single cigarette rapidly reduces combined concentrations of nitrate and nitrite and concentrations of antioxidants in plasma. Circulation 2002, 105:1155-1157.

14. Howard G, Wagenknecht LE, Cai J, Cooper L, Kraut MA, Toole JF: Cigarette smoking and other risk factors for silent cerebral infarction in the general population. Stroke 1998, 29:913-917.

15. Shinton R, Beevers G: Meta-analysis of relation between cigarette smoking and stroke. BMJ 1989, 298:789-794.

16. Mannami T, Iso H, Baba S, Sasaki S, Okada K, Konishi M, Tsugane S: Cigarette smoking and risk of stroke and its subtypes among middleaged Japanese men and women: the JPHC Study Cohort I. Stroke 2004, 35:1248-1253.

17. Miller GJ, Bauer KA, Cooper JA, Rosenberg RD: Activation of the coagulant pathway in cigarette smokers. Thromb Haemost 1998, 79:549-553.

18. Mast $H$, Thompson JL, Lin IF, Hofmeister C, Hartmann A, Marx P, Mohr JP, Sacco RL: Cigarette smoking as a determinant of high-grade carotid artery stenosis in Hispanic, black, and white patients with stroke or transient ischemic attack. Stroke 1998, 29:908-912.

19. Gill JS, Shipley MJ, Tsementzis SA, Hornby R, Gill SK, Hitchcock ER, Beevers DG: Cigarette smoking. A risk factor for hemorrhagic and nonhemorrhagic stroke. Arch Intern Med 1989, 149:2053-2057.

20. Epperlein MM, Nourooz-Zadeh J, Noronha-Dutra AA, Woolf N: Nitric oxide in cigarette smoke as a mediator of oxidative damage. Int J Exp Pathol 1996, 77:197-200.

21. Baldeiras I, Santana I, Proenca MT, Garrucho MH, Pascoal R, Rodrigues A, Duro D, Oliveira CR: Oxidative Damage and Progression to Alzheimer's Disease in Patients with Mild Cognitive Impairment. J Alzheimers Dis 2010.

22. Seet RC, Lee CY, Lim EC, Tan JJ, Quek AM, Chong WL, Looi WF, Huang SH, Wang $\mathrm{H}$, Chan $\mathrm{YH}$, et al: Oxidative damage in Parkinson disease: Measurement using accurate biomarkers. Free Radic Biol Med 2010, 48:560-566.

23. Dal Pizzol F, Ritter C, Cassol-Jr OJ, Rezin GT, Petronilho F, Zugno Al, Quevedo J, Streck EL: Oxidative mechanisms of brain dysfunction during sepsis. Neurochem Res 2010, 35:1-12.

24. Stangherlin EC, Luchese C, Ardais AP, Nogueira CW: Passive smoke exposure induces oxidative damage in brains of rat pups: Protective role of diphenyl diselenide. Inhal Toxicol 2009, 21:868-874.

25. Hossain M, Sathe T, Fazio V, Mazzone P, Weksler B, Janigro D, Rapp E, Cucullo L: Tobacco smoke: a critical etiological factor for vascular impairment at the blood-brain barrier. Brain Res 2009, 1287:192-205.

26. Schreibelt G, Kooij G, Reijerkerk A, van Doorn R, Gringhuis SI, van der PS, Weksler BB, Romero IA, Couraud PO, Piontek J, et al: Reactive oxygen species alter brain endothelial tight junction dynamics via RhoA, PI3 kinase, and PKB signaling. FASEB J 2007, 21:3666-3676.

27. Rao R: Oxidative stress-induced disruption of epithelial and endothelial tight junctions. Front Biosci 2008, 13:7210-7226.

28. Zou N, Hong J, Dai QY: Passive cigarette smoking induces inflammatory injury in human arterial walls. Chin Med J (Engl) 2009, 122:444-448.

29. Westbrook DG, Anderson PG, Pinkerton KE, Ballinger SW: Perinatal tobacco smoke exposure increases vascular oxidative stress and mitochondrial damage in non-human primates. Cardiovasc Toxicol 2010, 10:216-226. 
30. Haorah J, Ramirez SH, Schall K, Smith D, Pandya R, Persidsky Y: Oxidative stress activates protein tyrosine kinase and matrix metalloproteinases leading to blood-brain barrier dysfunction. J Neurochem 2007, 101:566-576.

31. Hutamekalin P, Farkas AE, Orbok A, Wilhelm I, Nagyoszi P, Veszelka S, Deli MA, Buzas K, Hunyadi-Gulyas E, Medzihradszky KF, et al: Effect of nicotine and polyaromtic hydrocarbons on cerebral endothelial cells. Cell Biol Int 2008, 32:198-209.

32. Pun PB, Lu J, Moochhala S: Involvement of ROS in BBB dysfunction. Free Radic Res 2009, 43:348-364.

33. Van der GA, Wouters D, Van Der Pol SM, Huizinga R, Ronken E, Adamson P, Greenwood J, Dijkstra CD, de Vries HE: Reactive oxygen species enhance the migration of monocytes across the blood-brain barrier in vitro. FASEB J 2001, 15:1852-1854.

34. Whincup PH, Gilg JA, Emberson JR, Jarvis MJ, Feyerabend C, Bryant A, Walker M, Cook DG: Passive smoking and risk of coronary heart disease and stroke: prospective study with cotinine measurement. BMJ 2004, 329:200-205.

35. Paulson JR, Yang T, Selvaraj PK, Mdzinarishvili A, Van der Schyf CJ, Klein J, Bickel $U$, Abbruscato TJ: Nicotine exacerbates brain edema during in vitro and in vivo focal ischemic conditions. J Pharmacol Exp Ther 2010, 332:371-379

36. Djordjevic VB: Free radicals in cell biology. Int Rev Cytol 2004, 237:57-89.

37. Klaunig JE, Kamendulis LM, Hocevar BA: Oxidative stress and oxidative damage in carcinogenesis. Toxicol Pathol 2010, 38:96-109.

38. Kong Q, Lin CL: Oxidative damage to RNA: mechanisms, consequences, and diseases. Cell Mol Life Sci 2010, 67:1817-1829.

39. Reuter S, Gupta SC, Chaturvedi MM, Aggarwal BB: Oxidative stress, inflammation, and cancer: How are they linked? Free Radic Biol Med 2010.

40. Uttara B, Singh AV, Zamboni P, Mahajan RT: Oxidative stress and neurodegenerative diseases: a review of upstream and downstream antioxidant therapeutic options. Curr Neuropharmacol 2009, 7:65-74.

41. Tabet N, Mantle D, Orrell M: Free radicals as mediators of toxicity in Alzheimer's disease: a review and hypothesis. Adverse Drug React Toxicol Rev 2000, 19:127-152.

42. Valko M, Izakovic M, Mazur M, Rhodes CJ, Telser J: Role of oxygen radicals in DNA damage and cancer incidence. Mol Cell Biochem 2004, 266:37-56.

43. Pryor WA, Stone K, Zang LY, Bermudez E: Fractionation of aqueous cigarette tar extracts: fractions that contain the tar radical cause DNA damage. Chem Res Toxicol 1998, 11:441-448.

44. DeMarini DM: Genotoxicity of tobacco smoke and tobacco smoke condensate: a review. Mutat Res 2004, 567:447-474.

45. Fang YZ, Yang S, Wu G: Free radical homeostasis. Sheng Li Ke Xue Jin Zhan 2004, 35:199-204.

46. Valko M, Leibfritz D, Moncol J, Cronin MT, Mazur M, Telser J: Free radicals and antioxidants in normal physiological functions and human disease. Int J Biochem Cell Biol 2007, 39:44-84.

47. Varela-Carver A, Parker $\mathrm{H}$, Kleinert $\mathrm{C}$, Rimoldi $\mathrm{O}$ : Adverse effects of cigarette smoke and induction of oxidative stress in cardiomyocytes and vascular endothelium. Curr Pharm Des 2010, 16:2551-2558.

48. Valavanidis A, Vlachogianni T, Fiotakis K: Tobacco smoke: involvement of reactive oxygen species and stable free radicals in mechanisms of oxidative damage, carcinogenesis and synergistic effects with other respirable particles. Int J Environ Res Public Health 2009, 6:445-462.

49. Pryor WA, Stone K: Oxidants in cigarette smoke. Radicals, hydrogen peroxide, peroxynitrate, and peroxynitrite. Ann N Y Acad Sci 1993, 686:12-27

50. Sobczak A, Golka D, Szoltysek-Boldys I: The effects of tobacco smoke on plasma alpha- and gamma-tocopherol levels in passive and active cigarette smokers. Toxicol Lett 2004, 151:429-437.

51. Dietrich M, Block G, Norkus EP, Hudes M, Traber MG, Cross CE, Packer L: Smoking and exposure to environmental tobacco smoke decrease some plasma antioxidants and increase gamma-tocopherol in vivo after adjustment for dietary antioxidant intakes. Am J Clin Nutr 2003, 77:160-166

52. Willcox JK, Ash SL, Catignani GL: Antioxidants and prevention of chronic disease. Crit Rev Food Sci Nutr 2004, 44:275-295.

53. Kelly G: The interaction of cigarette smoking and antioxidants. Part III: ascorbic acid. Altern Med Rev 2003, 8:43-54.

54. Kelly GS: The interaction of cigarette smoking and antioxidants. Part 2: alpha-tocopherol. Altern Med Rev 2002, 7:500-511.
55. Kelly GS: The interaction of cigarette smoking and antioxidants. Part I: diet and carotenoids. Altern Med Rev 2002, 7:370-388.

56. Traber MG, van d V, Reznick AZ, Cross CE: Tobacco-related diseases. Is there a role for antioxidant micronutrient supplementation? Clin Chest Med 2000, 21:173-87, x..

57. Preedy VR, Watson RR, Sherma Z: Humana Press; 2010.

58. Johnston CS, Martin $\sqcup$, Cai X: Antihistamine effect of supplemental ascorbic acid and neutrophil chemotaxis. J Am Coll Nutr 1992, 11:172-176.

59. van Horssen J, Schreibelt G, Drexhage J, Hazes T, Dijkstra CD, van d V, de Vries HE: Severe oxidative damage in multiple sclerosis lesions coincides with enhanced antioxidant enzyme expression. Free Radic Biol Med 2008, 45:1729-1737.

60. Montecinos V, Guzman P, Barra V, Villagran M, Munoz-Montesino C, Sotomayor K, Escobar E, Godoy A, Mardones L, Sotomayor P, et al: Vitamin $C$ is an essential antioxidant that enhances survival of oxidatively stressed human vascular endothelial cells in the presence of a vast molar excess of glutathione. J Biol Chem 2007, 282:15506-15515.

61. Smith AR, Visioli F, Hagen TM: Vitamin C matters: increased oxidative stress in cultured human aortic endothelial cells without supplemental ascorbic acid. FASEB J 2002, 16:1102-1104.

62. Panda K, Chattopadhyay R, Ghosh MK, Chattopadhyay DJ, Chatterjee IB: Vitamin C prevents cigarette smoke induced oxidative damage of proteins and increased proteolysis. Free Radic Biol Med 1999, 27:1064-1079.

63. van Dam B, van Hinsbergh WW, Stehouwer CD, Versteilen A, Dekker $H$, Buytenhek R, Princen HM, Schalkwijk CG: Vitamin E inhibits lipid peroxidation-induced adhesion molecule expression in endothelial cells and decreases soluble cell adhesion molecules in healthy subjects. Cardiovasc Res 2003, 57:563-571.

64. Wagner BA, Buettner GR, Burns CP: Vitamin E slows the rate of free radical-mediated lipid peroxidation in cells. Arch Biochem Biophys 1996, 334:261-267.

65. Brown KM, Morrice PC, Duthie GG: Vitamin E supplementation suppresses indexes of lipid peroxidation and platelet counts in blood of smokers and nonsmokers but plasma lipoprotein concentrations remain unchanged. Am J Clin Nutr 1994, 60:383-387.

66. Cucullo L, Hossain M, Rapp E, Manders T, Janigro D: Development of a humanized in vitro blood-brain barrier model to screen for brain penetration of antiepileptic drugs. Epilepsia 2006.

67. Cucullo L, McAllister M, Kight K, Krizanac-Bengez L, Marroni M, Mayberg M, Stanness $K$, Janigro D: A new dynamic in vitro model for the multidimensional study of astrocyte-endothelial cell interactions at the blood-brain barrier. Brain Res 2002, 951:243

68. Santaguida S, Janigro D, Hossain M, Oby E, Rapp E, Cucullo L: Side by side comparison between dynamic versus static models of blood-brain barrier in vitro: A permeability study. Brain Res 2006, 1109:1-13.

69. Nakayama T, Church DF, Pryor WA: Quantitative analysis of the hydrogen peroxide formed in aqueous cigarette tar extracts. Free Radic Biol Med 1989, 7:9-15.

70. Takanami Y, Moriyama T, Kosaka Y, Nakayama T: Analysis of hydrogen peroxide in an aqueous extract of cigarette smoke and effect of $\mathrm{pH}$ on the yield. Biosci Biotechnol Biochem 2009, 73:2222-2225.

71. Cucullo L, Hossain M, Puvenna V, Marchi N, Janigro D: The role of shear stress in Blood-Brain Barrier endothelial physiology. BMC Neurosci 2011, 12:40

72. Bernacki J, Dobrowolska A, Nierwinska K, Malecki A: Physiology and pharmacological role of the blood-brain barrier. Pharmacol Rep 2008, 60:600-622.

73. Weiss N, Miller F, Cazaubon S, Couraud PO: The blood-brain barrier in brain homeostasis and neurological diseases. Biochim Biophys Acta 2009, 1788:842-857.

74. Abbott NJ, Revest PA, Romero IA: Astrocyte-endothelial interaction: physiology and pathology. Neuropathol Appl Neurobiol 1992, 18:424-433.

75. Arnson $Y$, Shoenfeld $Y$, Amital H: Effects of tobacco smoke on immunity, inflammation and autoimmunity. J Autoimmun 2009.

76. Vajdovich $P$ : Free radicals and antioxidants in inflammatory processes and ischemia-reperfusion injury. Vet Clin North Am Small Anim Pract 2008, 38:31-123, v..

77. Khanna AK, XU J, Uber PA, Burke AP, Baquet C, Mehra MR: Tobacco smoke exposure in either the donor or recipient before transplantation 
accelerates cardiac allograft rejection, vascular inflammation, and graft loss. Circulation 2009, 120:1814-1821.

78. Nordskog BK, Blixt AD, Morgan WT, Fields WR, Hellmann GM: Matrixdegrading and pro-inflammatory changes in human vascular endothelial cells exposed to cigarette smoke condensate. Cardiovasc Toxicol 2003, 3:101-117.

79. Masubuchi T, Koyama S, Sato E, Takamizawa A, Kubo K, Sekiguchi M, Nagai S, Izumi T: Smoke extract stimulates lung epithelial cells to release neutrophil and monocyte chemotactic activity. Am J Pathol 1998, 153:1903-1912.

80. Verma S, Wang CH, Li SH, Dumont AS, Fedak PW, Badiwala MV, Dhillon B, Weisel RD, Li RK, Mickle DA, et al: A self-fulfilling prophecy: C-reactive protein attenuates nitric oxide production and inhibits angiogenesis. Circulation 2002, 106:913-919.

81. Rahman I, MacNee W: Role of oxidants/antioxidants in smoking-induced lung diseases. Free Radic Biol Med 1996, 21:669-681.

82. Pincemail J, Vanbelle S, Degrune F, Cheramy-Bien JP, Charlier C, Chapelle JP, Giet D, Collette G, Albert A, Defraigne JO: Lifestyle Behaviours and Plasma Vitamin C and beta-Carotene Levels from the ELAN Population (Liege, Belgium). J Nutr Metab 2011, 2011:494370.

83. Sharma MK, Buettner GR: Interaction of vitamin C and vitamin E during free radical stress in plasma: an ESR study. Free Radic Biol Med 1993, 14:649-653.

84. Abbruscato TJ, Lopez SP, Mark KS, Hawkins BT, Davis TP: Nicotine and cotinine modulate cerebral microvascular permeability and protein expression of ZO-1 through nicotinic acetylcholine receptors expressed on brain endothelial cells. J Pharm Sci 2002, 91:2525-2538

85. Darley-Usmar VM, Hogg N, O'Leary VJ, Wilson MT, Moncada S: The simultaneous generation of superoxide and nitric oxide can initiate lipid peroxidation in human low density lipoprotein. Free Radic Res Commun 1992, 17:9-20.

86. Su Y, Han W, Giraldo C, De Li Y, Block ER: Effect of cigarette smoke extract on nitric oxide synthase in pulmonary artery endothelial cells. Am J Respir Cell Mol Biol 1998, 19:819-825.

87. Toda N, Toda H: Nitric oxide-mediated blood flow regulation as affected by smoking and nicotine. Eur J Pharmacol 2010, 649:1-13.

88. Leone A: Does Smoking Act as a Friend or Enemy of Blood Pressure? Let Release Pandora's Box. Cardiol Res Pract 2011, 2011:264894.

89. Chalon S, Moreno H Jr, Benowitz NL, Hoffman BB, Blaschke TF: Nicotine impairs endothelium-dependent dilatation in human veins in vivo. Clin Pharmacol Ther 2000, 67:391-397.

90. Jensen EX, Fusch C, Jaeger P, Peheim E, Horber FF: Impact of chronic cigarette smoking on body composition and fuel metabolism. J Clin Endocrinol Metab 1995, 80:2181-2185.

91. Gorman D, Drewry A, Huang YL, Sames C: The clinical toxicology of carbon monoxide. Toxicology 2003, 187:25-38.

92. Stoller KP: Hyperbaric oxygen and carbon monoxide poisoning: a critical review. Neurol Res 2007, 29:146-155.

93. Shimosegawa E, Hatazawa J, Nagata K, Okudera T, Inugami A, Ogawa T, Fujita H, Itoh H, Kanno I, Uemura K: Cerebral blood flow and glucose metabolism measurements in a patient surviving one year after carbon monoxide intoxication. J Nucl Med 1992, 33:1696-1698.

94. Rizzo MR, Abbatecola AM, Barbieri M, Vietri MT, Cioffi M, Grella R, Molinari A, Forsey R, Powell J, Paolisso G: Evidence for anti-inflammatory effects of combined administration of vitamin $\mathrm{E}$ and $\mathrm{C}$ in older persons with impaired fasting glucose: impact on insulin action. J Am Coll Nutr 2008, 27:505-511.

95. Meyer J, Tauh J, Galla HG: The susceptibility of cerebral endothelial cells to astroglial induction of blood-brain barrier enzymes depends on their proliferative state. J Neurochem 1991, 57:1971-1977.

96. Barth $A$, Newell DW, Nguyen LB, Winn HR, Wender R, Meno JR, Janigro D: Neurotoxicity in organotypic hippocampal slices mediated by adenosine analogues and nitric oxide. Brain Res 1997, 762:79-88

97. Janigro D, Nguyen TS, Gordon EL, Winn HR: Physiological properties of ATP-activated cation channels in rat brain microvascular endothelial cells. Am J Physiol 1996, 270:H1423-H1434.

doi:10.1186/1471-2202-12-92

Cite this article as: Hossain et al.: In Vitro Assessment of Tobacco Smoke Toxicity at the BBB: Do Antioxidant Supplements Have a Protective Role? BMC Neuroscience 2011 12:92.

\section{Submit your next manuscript to BioMed Central and take full advantage of:}

- Convenient online submission

- Thorough peer review

- No space constraints or color figure charges

- Immediate publication on acceptance

- Inclusion in PubMed, CAS, Scopus and Google Scholar

- Research which is freely available for redistribution 